\title{
PRODUÇÃO DE CAROTENOIDES: MICRORGANISMOS COMO FONTE DE PIGMENTOS NATURAIS
}

Eunice Valduga*, Pihetra Oliveira Tatsch, Lídia Tiggemann, Helen Treichel, Geciane Toniazzo, Jamile Zeni e Marco Di Luccio Departamento de Engenharia de Alimentos, Universidade Regional Integrada, Campus de Erechim, Av. Sete de Setembro, 1621, 99700-000 Erechim - RS, Brasil

Agenor Fúrigo Júnior

Departamento de Engenharia Química e de Alimentos, Universidade Federal de Santa Catarina, 88040-900 Florianópolis - SC, Brasil

Recebido em 5/9/08; aceito em 29/4/09; publicado na web em 28/10/09

\begin{abstract}
CAROTENOIDS PRODUCTION: MICROORGANISMS AS SOURCE OF NATURAL DYES. Carotenoids are natural dyes synthesized by plants, algae and microorganisms. Application in many sectors can be found, as food dyeing and supplementation, pharmaceuticals, cosmetics and animal feed. Recent investigations have shown their ability to reduce the risks for many degenerative diseases like cancer, heart diseases, cataract and macular degeneration. An advantage of microbial carotenoids is the fact that the cultivation in controlled conditions is not dependent of climate, season or soil composition. In this review the advances in bio-production of carotenoids are presented, discussing the main factors that influence the microbial production of these dyes in different systems.
\end{abstract}

Keywords: carotenoids; microorganisms; carotenogenesis.

\section{INTRODUÇÃO}

Os carotenoides são corantes naturais responsáveis pelas cores amarelas, laranja e vermelho, utilizados nas indústrias alimentícia, farmacêutica, de cosméticos e ração. Além de seu amplo uso como corantes e no enriquecimento de alimentos, também são utilizados devido a sua atividade pró-vitamínica A e as propriedades que resultam em possíveis funções biológicas benéficas à saúde, tais como o fortalecimento do sistema imunológico e a diminuição do risco de doenças degenerativas (certos tipos de câncer, doenças cardiovasculares, degeneração macular e catarata). ${ }^{1}$

A produção comercial de carotenoides a partir de microrganismos concorre principalmente com a produção sintética por procedimentos químicos. Atualmente, os carotenoides utilizados industrialmente são obtidos por via química ou extração de plantas e/ou algas. Entretanto, devido à preocupação com o uso de aditivos químicos em alimentos, houve um crescente interesse nos carotenoides obtidos naturalmente por processos biotecnológicos. Além da conotação natural, os produtos obtidos por produção microbiana podem ser obtidos em curto prazo, em qualquer época do ano.

A produção biotecnológica de carotenoides vem se destacando devido a fatores tais como possibilidade de utilização de substratos de baixo custo para a bioprodução; denominação de substâncias naturais; pequeno espaço para produção, não estando sujeita às condições ambientais como clima, estação do ano ou composição do solo, e controle das condições de cultivo. ${ }^{2}$

Muitos microrganismos produzem carotenoides, porém nem todos são industrialmente interessantes. As leveduras destacam-se pelo seu uso como fonte proteica, capacidade de crescimento em substratos de baixo custo e alto teor de açúcar. Os tipos de carotenoides e a quantidade relativa destes podem variar dependendo das condições do meio de cultura, temperatura, $\mathrm{pH}$, taxa de aeração e luminosidade. ${ }^{3}$

Dentre os estudos realizados, destaca-se a produção de carotenoides pelos microrganismos Rhodotorula, ${ }^{4,5}$ Phaffia rhodozyma, ${ }^{6-8}$ Sporobolomyces,${ }^{9,10}$ Blakeslea trispora, ${ }^{11,12}$ Dunaliella salina ${ }^{13,14}$ e Haematococcus pluvialis, ${ }^{15-18}$ sendo que os carotenoides naturais mais investigados são a astaxantina, $\beta$-caroteno, cantaxantina, toruleno e licopeno.

*e-mail: veunice@uricer.edu.br
Há algumas décadas as condições ambientais e os estimulantes da carotenogênese vêm sendo examinados, a fim de melhorar a produção de carotenoides e avaliar os microrganismos produtores de pigmento (microalgas, fungos e bactérias). A composição do meio de cultivo, tais como a fonte de carbono e nitrogênio, ${ }^{19}$ presença de metais e sais ${ }^{20}$ e agentes químicos, ${ }^{2}$ é fator que necessita de investigação para um aumento na produção. Além disso, as condições ambientais também merecem atenção, como a luminosidade, ${ }^{17,21}$ agitação e aeração ${ }^{6} \mathrm{e} \mathrm{pH} \cdot{ }^{22}$

\section{PROPRIEDADES E FUNÇÕES DOS CAROTENOIDES}

Os carotenoides são pigmentos naturais responsáveis pelas cores amarelas, laranja e vermelho de muitos alimentos, tais como frutas, vegetais, gema de ovo, alguns peixes, como salmão e truta, e crustáceos. ${ }^{23}$ Além de colorir, os carotenoides possuem atividades biológicas importantes destacando-se a inibição de doenças onde os radicais livres apresentam papel fundamental, como arteriosclerose, catarata, degeneração macular, esclerose múltipla, câncer, doenças degenerativas e cardiovasculares. ${ }^{23-25}$

O licopeno, caroteno presente em produtos de tomate, previne a oxidação do LDL e reduz o risco do desenvolvimento de arteriosclerose e doenças coronárias, ${ }^{26}$ além disso, outras pesquisas sugerem que este carotenoide pode reduzir o câncer de próstata, pulmão, pele e bexiga. ${ }^{27}$ Nas indústrias de alimentos, os carotenoides são utilizados principalmente como corantes, com os objetivos de repor a cor perdida durante o processamento e armazenamento, colorir os alimentos incolores e uniformizar a coloração de alguns produtos alimentícios. Mais recentemente, com o crescente interesse pela saúde, os carotenoides também têm sido adicionados aos alimentos a fim de enriquecer o produto. São também precursores de muitos compostos químicos importantes, responsáveis pelo aroma de alguns alimentos, fragrâncias de algumas flores, ${ }^{28}$ coloração específica e fotoproteção. ${ }^{29}$

Industrialmente os carotenoides, tais como $\beta$-caroteno e astaxantina, são utilizados como corantes naturais para alimentos ou adicionados em ração para aquicultura. ${ }^{24} \mathrm{~A}$ astaxantina é um pigmento encontrado em animais aquáticos, tais como lagosta, siri e camarão. Este pigmento protege contra radicais livres, peroxidação lipídica, danos oxidativos ao colesterol LDL, oxidação dos ácidos graxos 
poli-insaturados essenciais e proteção contra os efeitos da luz UV, membranas celulares, células e tecidos. ${ }^{22}$

Devido à alta taxa de insaturação fatores tais como calor, luz e ácidos ocasionam isomerização dos carotenoides trans, que é a forma mais estável na natureza, para a forma cis, promovendo ligeira perda de cor e atividade pró-vitamínica. Os carotenoides são também susceptíveis às oxidações enzimáticas ou não enzimáticas, que dependem da estrutura do carotenoide, disponibilidade de oxigênio, presença de enzimas, metais, pró-oxidantes e antioxidantes, alta temperatura e exposição à luz. ${ }^{30}$

Os pigmentos podem absorver luz especificamente na região do ultravioleta (UV) e visível do espectro, o restante é transmitido ou refletido, e apresentam cor. A estrutura responsável pela absorção da luz é o grupamento cromóforo, que nos carotenoides se caracteriza pelas duplas ligações conjugadas. Cada carotenoide é caracterizado por um espectro de absorção eletrônica. Assim, a espectroscopia de absorção é uma importante técnica na análise de carotenoides. ${ }^{31}$

\section{ESTRUTURA E BIOSSÍNTESE DOS CAROTENOIDES}

Os carotenoides são isoprenoides lipofílicos sintetizados por todos os microrganismos fotossintéticos (incluindo plantas, algas e cianobactérias), e também por algumas bactérias não-fotossintéticas e fungos. Duas classes de carotenoides são encontradas na natureza: os carotenos, tais como $\beta$-caroteno, hidrocarbonetos lineares que podem ser ciclizados em uma ou ambas as extremidades da molécula; e os derivados oxigenados de carotenos, como luteína, violaxantina, neoxantina e zeaxantina, denominados xantofilas. ${ }^{32}$

A maioria dos carotenoides são tetraterpenoides $\mathrm{C}_{40}$ compostos de 8 unidades isoprenoides, ligados de tal forma que a molécula é linear e simétrica, com a ordem invertida no centro. A estrutura básica acíclica $\mathrm{C}_{40}$ pode ser modificada por hidrogenação, desidrogenação, ciclização ou oxidação, conforme demonstrado na Figura 1. A característica de absorção de luz destes pigmentos dá-se devido à cadeia de duplas ligações conjugadas que atua como cromóforo, sendo necessário, aproximadamente, sete ligações duplas conjugadas para que o carotenoide apresente coloração. O sistema de duplas ligações conjugadas também confere a estes pigmentos alta reatividade quími ca, podendo ser facilmente isomerizados e oxidados, principalmente quando submetidos a condições não controladas de processamento e/ou estocagem, mais especificamente em produtos naturais (frutas). Além disso, o calor, a luz, o oxigênio e enzimas como lipoxigenase e/ou ácidos presentes em frutas levam a alterações ou parcial des-

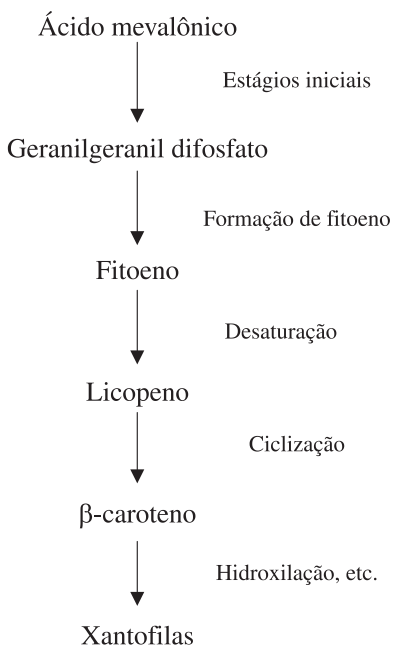

Figura 1. Fluxograma dos estágios da biossíntese de carotenoides ${ }^{2}$ truição dos pigmentos. A exposição destes a tais agentes resulta na formação de isômeros cis, epóxidos, diminuição da cor, perda da atividade pró-vitamínica A e quebra da cadeia. ${ }^{33-35}$

A Figura 2 apresenta a estrutura de alguns xantofilas (zeaxantina, luteína, criptoxantina e astaxantina) e Carotenos (neurosporeno, licopeno, $\beta$-caroteno e $\alpha$-caroteno). Os carotenoides são tetraterpenos e sua biossíntese apresenta um padrão para todos os terpenoides. $\mathrm{O}$ primeiro precursor específico na biossíntese dos terpenoides é o ácido mevalônico. O ácido mevalônico, após uma série de reações, forma geranil difosfato $(10 \mathrm{C})$, farnesil difosfato $(15 \mathrm{C})$ e geranil-geranil difosfato $(20 \mathrm{C}){ }^{35}$

A dimerização de duas moléculas de geranil-geranil difosfato forma o fitoeno, sendo este o primeiro composto de quarenta carbonos, embora ainda sem coloração. Segue-se uma série de desaturações a partir do fitoeno para formar fitoflueno, $\zeta$-caroteno, neurosporeno e, finalmente licopeno, conforme demonstrado na Figura 3.

A ciclização pode ocorrer a partir do neurosporeno ou licopeno (Figura 4). O neurosporeno sofre ciclização em uma das extremidades, formando o anel $\beta$ de $\beta$-zeacaroteno ou o anel $\alpha$ de $\alpha$-caroteno. Estes dois carotenoides são transformados em $\gamma$-caroteno e $\delta$-caroteno, respectivamente, pela introdução de uma dupla ligação, estendendo o sistema de dupla ligação conjugadas. O licopeno pode também ser ciclizado em uma das extremidades, gerando $\gamma$-caroteno e $\delta$-caroteno. Estes carotenos monocíclicos sofrem ciclização na outra extremidade, resultando em $\beta$-caroteno e $\alpha$-caroteno, respectivamente. . $^{2,35}$

Após a formação dos carotenóides cíclicos, tem-se a introdução de substituintes, como a hidroxila, gerando xantofilas. Nas Figuras 5 e 6 , têm-se a formação das xantofilas a partir do $\alpha$-caroteno e $\beta$-caroteno, respectivamente.

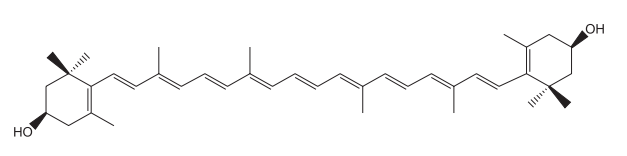

(a)
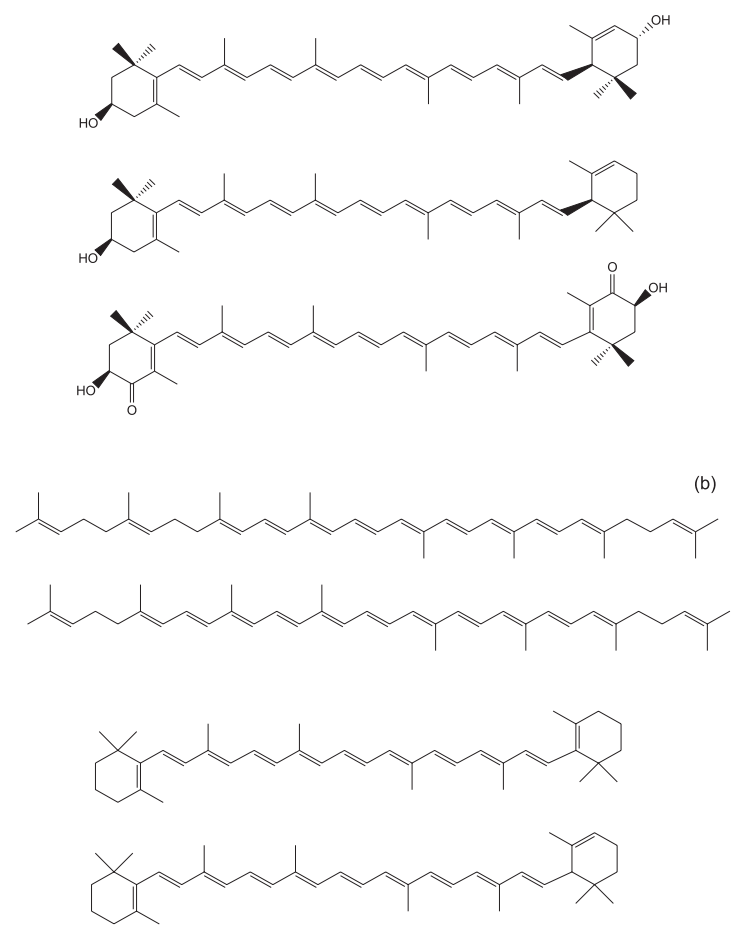

Figura 2. Estrutura dos carotenoides: (a) xantofilas - zeaxantina, luteína, criptoxantina e astaxantina, respectivamente; (b) carotenos - neurosporeno, licopeno, $\beta$-caroteno e $\alpha$-caroteno, respectivamente ${ }^{2}$ 


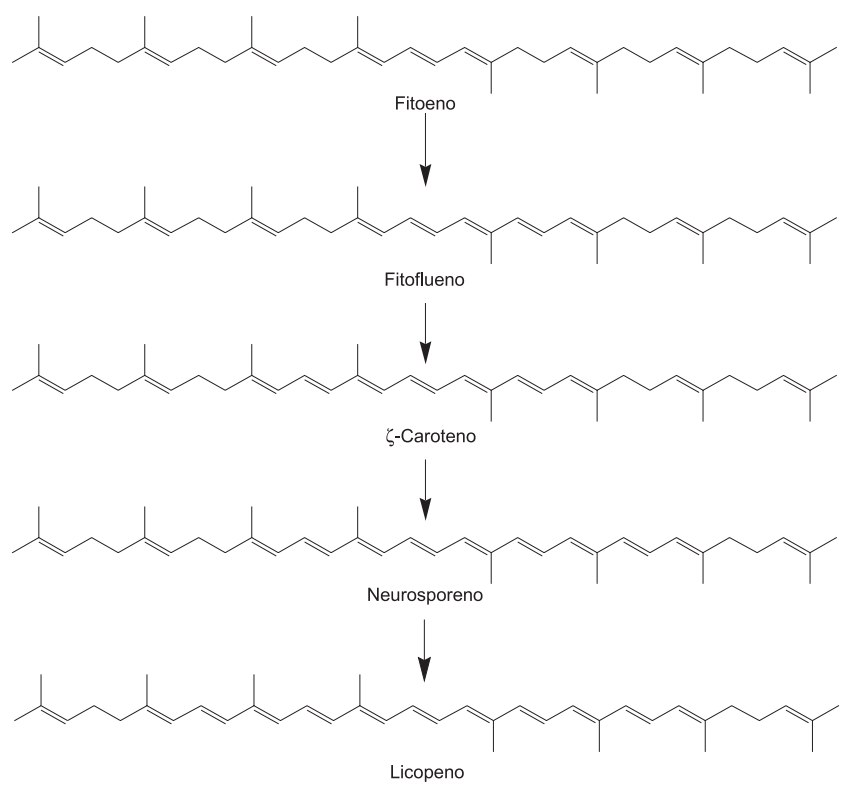

Figura 3. Estágios intermediários da biossíntese de carotenoides ${ }^{2}$

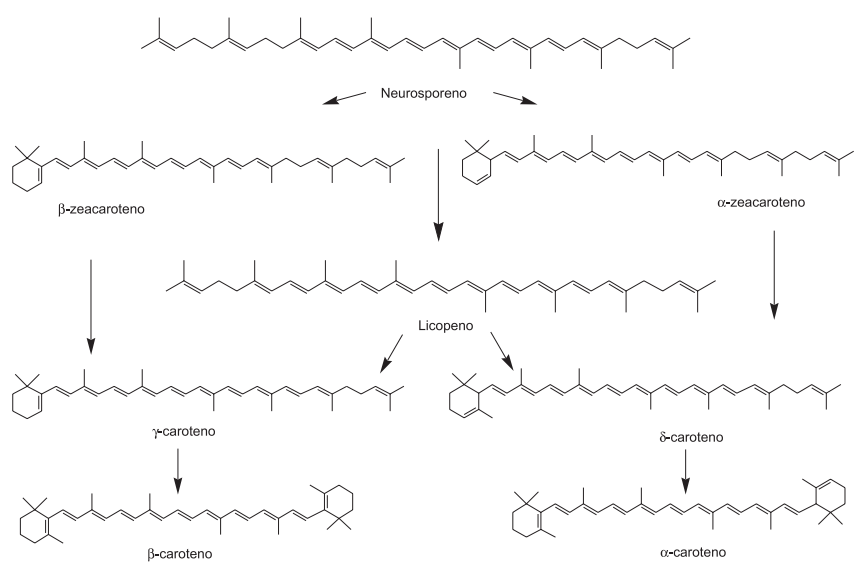

Figura 4. Ciclização dos carotenos acíclicos insaturados ${ }^{2}$

\section{MICRORGANISMOS PRODUTORES DE CAROTENOIDES}

Os carotenoides podem ser biossintetizados por microrganismos fotossintetizantes como, por exemplo, algas e cianobactérias (azuis e verdes), e por microrganismos não fotossintetizantes, como bactérias, fungos e leveduras. ${ }^{30}$

A produção de carotenoides pelo processo biotecnológico tem sido muito investigada, destacando-se a produção comercial de $\beta$-caroteno pelo fungo $B$. trispora,${ }^{36}$ pelas microalgas marinhas Dunaliella ${ }^{37}$ a produção de astaxantina pela microalga de água doce Haematococcus sp. e pela levedura $P$. rhodozyma. ${ }^{30}$

A microalga Dunaliella é rica em $\beta$-caroteno e outros carotenoides de grande aplicação. A Índia possui a maior indústria produtora desta microalga, onde o $\beta$-caroteno se destina ao uso farmacêutico. Outras grandes produtoras estão localizadas na Austrália, Estados Unidos, China, Mongólia e Japão; pequenas plantas também são encontradas no México, Chile, Cuba, Irã e Taiwan. ${ }^{38}$

A produção industrial de astaxantina por Haematococcus também apresenta grande interesse devido ao elevado valor comercial deste pigmento, e o grande crescimento do mercado da aquicultura. Os principais produtores mundiais estão localizados nos Estados Unidos, Japão e Índia. ${ }^{38}$

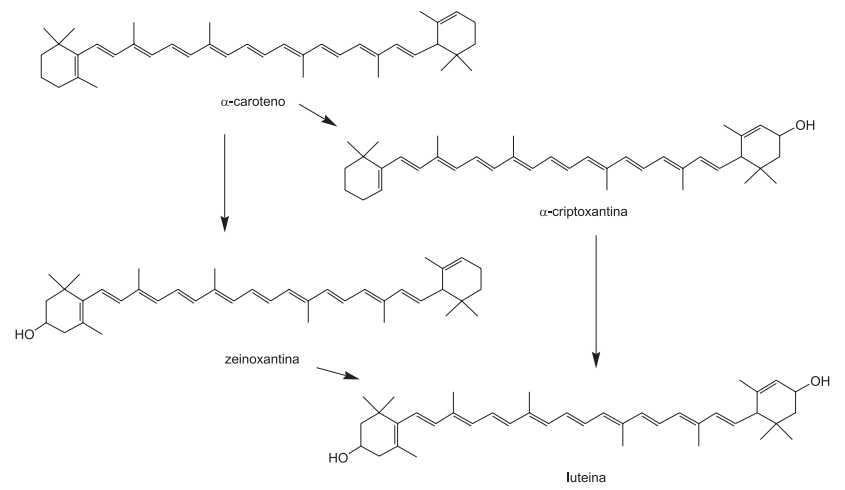

Figura 5. Formação de xantofilas a partir do carotenoide $\alpha$-caroteno ${ }^{2}$<smiles>CC1=C(/C=C/C(C)=C/C=C/C(C)=C/C=C/C=C(C)/C=C/C=C(C)/C=C/C2=C(C)CC(O)CC2(C)C)C(C)(C)CCC1</smiles>

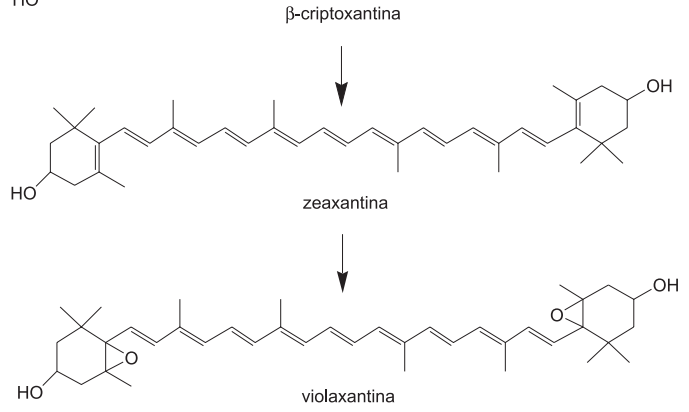

Figura 6. Formação de xantofilas a partir de $\beta$-caroteno ${ }^{2}$

A capacidade do cultivo de leveduras em meios com alto teor de açúcar torna estes microrganismos industrialmente interessantes. Leveduras, tais como Xanthophyllomyces dendrorhous, ${ }^{39-41}$ Rhodotorula glutinis, ${ }^{3,5,24,42}$ Rhodotorula mucilaginosa,${ }^{19}$ Sporobolomyces, ${ }^{9,}$ ${ }^{43,44}$ e $P$. rhodozyma, ${ }^{6,7,45,46}$ estão sendo estudadas com a finalidade de maximização e/ou otimização da bioprodução de carotenóides, visando a utilização industrial.

Na Tabela 1 estão apresentados os microrganismos com potencial para serem empregados na bioprodução dos principais carotenoides.

\section{FATORES QUE INFLUENCIAM A BIOPRODUÇÃO DE CAROTENOIDES}

A possibilidade da produção de corantes naturais em escala industrial e o elevado valor dos produtos tornam a produção biotecnológica de carotenoides uma área de intenso estudo. A produtividade de um bioprocesso em um dado sistema depende das condições nutricionais e físicas da cultura, afetando não somente o crescimento celular como a produção de pigmento. ${ }^{40}$ Sendo assim, os microrganismos acumulam vários tipos de carotenoides como resposta ao estresse das condições ambientais. ${ }^{25}$

Melhorar a eficiência da biossíntese de carotenoides pode aumentar a produção. Juntamente com as condições de cultivo, a biossíntese de carotenoides é conduzida pelo nível e atividade das enzimas biossintéticas e o fluxo total de carbono do sistema sintetizante. Assim, uma alta produção pode ser alcançada alterando-se o nível e a atividade destas enzimas 
Tabela 1. Microrganismos e carotenoides produzidos biotecnologicamente

Espécies $\quad$ Carotenoides principais

\section{Cianobactérias}

Anabaena variabilis ${ }^{30}$

Aphanizomenon flos-aqua ${ }^{30}$

Cantaxantina

Nostoc commune co $^{30}$

Cantaxantina

Nostochopsis lobatus ${ }^{71}$

Algas

Chlorela pyrenoidosa $a^{30}$

Luteína

Dictycoccus cinnabarinus ${ }^{30}$

Cantaxantina

Dunaliella salina ${ }^{58}$

Dunaliella tertiolecta ${ }^{58}$

Haematococcus pluvialis ${ }^{69}$

Spongiococcum excetricum ${ }^{30}$

$\beta$-caroteno

$\beta$-caroteno

Astaxantina

Luteína

\section{Fungos e leveduras}

Blakeslea trispora ${ }^{30}$

Dacrymyces deliquescens ${ }^{30}$

Phaffia rhodozyma ${ }^{6,7}$

Rhodosporidium $s p^{30}$

Rhodotorula glutinis ${ }^{50}$

Rhodotorula graminis s $^{20}$

Rhodotorula mucilaginosa ${ }^{50}$

Rhodotorula rubra ${ }^{59}$

Sporidiobolus salmonicolor ${ }^{63}$

Sporidiobolus $s p^{30}$

Sporobolomyces roseus ${ }^{43}$

Sporobolomyces ruberrimus ${ }^{44}$

Xanthophyllomyces dendrorhous ${ }^{22}$

Bactérias

Mycobacterium brevicaie ${ }^{30}$

Mycobacterium lacticola ${ }^{30}$

Rhodobacter sphaeroides ${ }^{71}$

Rhodococcus maris ${ }^{30}$

Streptomyces chrestomyceticus ${ }^{30}$ $\beta$-caroteno e licopeno

Luteína

Astaxantina e $\beta$-caroteno

Toruleno, $\beta$-caroteno

Torularrodina, $\beta$-caroteno, toruleno

Toruleno

Toruleno, torularrodina e $\beta$-caroteno

$\beta$-caroteno

$\beta$-caroteno

Toruleno, torularrodina, $\beta$-caroteno

Torularrodina, $\beta$-caroteno, toruleno

Torularrodina, $\beta$-caroteno,

Astaxantina

Cantaxantina

Astaxantina

Cantaxantina

Xantofilas

ou a via biossintética, pela utilização de uma abordagem molecular. ${ }^{25}$

Pode-se alcançar uma melhor produção de carotenoides com um custo efetivo, utilizando estimulantes no meio e ajustando as condições externas do cultivo. ${ }^{25}$ No estudo dos efeitos de vários agentes químicos (ácido acético, $\beta$-ionona, ácido mevalônico, difenilamina e outros aminoácidos) na biossíntese de carotenoides por leveduras do gênero Rhodotorula, a fim de aumentar e dirigir a carotenogênese, o ácido acético $(0,05$ a $1 \%)$ não apresentou influência no crescimento e na produção de pigmento nas leveduras $R$. glutinis e $R$. mucilaginosa,

porém a $\beta$-ionona $\left(10^{-3} \mathrm{M}\right)$ adicionada após $70 \mathrm{~h}$ do início do cultivo, inibiu o crescimento $(0,57 \mathrm{a} 0,49 \mathrm{~g} / 100 \mathrm{~mL})$ e a carotenogênese (1980 a $1701 \mu \mathrm{g} / \mathrm{L}$ ) da levedura $R$. glutinis, sendo observado comportamento semelhante para a $R$. mucilaginosa. O ácido mevalônico $(0,05 ; 0,1$ e $0,2 \%$ ) estimulou a formação de carotenoides em $120 \%$ para $R$. mucilaginosa e $35 \%$ para $R$. glutinis, sem afetar a produção de células. ${ }^{2}$

$\mathrm{O}$ efeito de traços de metais no crescimento de Rhodotorula graminis foi analisado observando-se uma influência seletiva no perfil de carotenoides. O efeito observado sobre a biossíntese dos carotenoides específicos nas leveduras vermelhas pode ser explicado hipotetizandose um possível mecanismo de ativação ou inibição causado por determinados íons metais sobre enzimas carotenogênicas específicas. ${ }^{20}$

Dentre os trabalhos que utilizam biorreator para a bioprodução, encontra-se o cultivo de $R$. glutinis,${ }^{47}$ onde se utilizou um biorreator de $5 \mathrm{~L}$ agitado mecanicamente, obtendo torularrodina $(61,7 \%)$ como carotenoide majoritário, seguido de toruleno e $\beta$-caroteno. No cultivo da microalga $D$. salina ${ }^{48}$ em fotobiorreator tubular fechado de $55 \mathrm{~L}$, com um sistema de air-lift para recirculação de células, observou-se um aumento na produção de $\beta$-caroteno e luteína. Uma concentração máxima de $27 \mathrm{mg} / \mathrm{L}$ foi alcançada no cultivo de astaxantina por $X$. dendrorhous $^{22}$ em fermentador agitado mecanicamente sob $\mathrm{pH}$ controlado ( $\mathrm{pH}$ 6,0 nas primeiras $80 \mathrm{~h}$, seguido de $\mathrm{pH} 4,0$ até $144 \mathrm{~h}$ de cultivo), com volume de trabalho de 20 L e 3 impelidores de 6 pás cada.

Na produção de astaxantina por X. dendrorhous e Bacillus circulans $^{39}$ em biorreator de 1,5 L, com agitação constante a $400 \mathrm{rpm}$, aeração 3,6 vvm, pH 6,5 e temperatura variando de 30 a $34{ }^{\circ} \mathrm{C}$, obteve-se $96 \%$ do pigmento extraído ( 3370 $\mu \mathrm{g} / \mathrm{L})$ após $48 \mathrm{~h}$ de fermentação em condições ótimas.

Ramírez e colaboradores ${ }^{46}$ realizaram a análise da produção de astaxantina por $P$. rhodozyma em batelada alimentada em biorreator de $3 \mathrm{~L}, 20^{\circ} \mathrm{C}$, pH 6,0, $900 \mathrm{rpm}$ e vazão de ar de 1,5 L/min. A cada mudança de $\mathrm{pH}$ (de ácido para alcalino) causada pela atividade metabólica das leveduras, o sistema de alimentação era ativado. As fontes de carbono e nitrogênio foram mantidas entre 15 e $25 \mathrm{~g} / \mathrm{L}$ e 0,5 a 1,0 g/L, respectivamente. A vazão de ar foi elevada $0,2 \mathrm{~L} / \mathrm{min}$ a cada $12 \mathrm{~h}$ até atingir $2,6 \mathrm{~L} / \mathrm{min}$. A suplementação de nutrientes (300 g/L suco de tâmara, 1,6 g/L de extrato de levedura, $10 \mathrm{~g} / \mathrm{L}$ ureia) adequada incrementou a formação de astaxantina e biomassa. A máxima produção de astaxantina alcançou $24 \mathrm{mg} / \mathrm{L}$, enquanto que a formação de biomassa foi $39 \mathrm{~g} / \mathrm{L}$.

No cultivo de Sporidiobolus salmonicolor CBS 2636 em biorreator, Tatsch ${ }^{49}$ obteve uma concentração máxima de carotenoides totais de 3318,6 $\mu \mathrm{g} / \mathrm{L}$ nas condições: $25^{\circ} \mathrm{C}$, pH inicial 4,0, $180 \mathrm{rpm}$, taxa de aeração de $1,5 \mathrm{vvm}, 80 \mathrm{~g} / \mathrm{L}$ de glicose, $15 \mathrm{~g} / \mathrm{L}$ de peptona e $5 \mathrm{~g} / \mathrm{L}$ de extrato de malte.

\section{Efeito da composição do meio de cultivo}

A sacarose e a glicose são as formas de carbono mais comumente utilizadas na bioprodução de carotenoides. O uso de glicose levou a maiores rendimentos na produção específica de carotenoides $(1000 \mu \mathrm{g} / \mathrm{g})$ por Rhodotorula sp. ${ }^{50}$ Porém, na produção de astaxantina por $P$. rhodozyma, ${ }^{51}$ verificou-se que concentrações altas de glicose inibem a carotenogênese, enquanto que a sacarose, maltose e celobiose foram os dissacarídeos que produziram melhores resultados. Um aumento de até 12 vezes na produção de $\beta$-caroteno foi observado no cultivo de P. rhodozyma em meio com $5 \%(\mathrm{~m} / \mathrm{v})$ de glicose.

A eficiência da utilização de farinha hidrolisada de resíduo de feijão e extrato de batata doce, como principais fontes de nitrogênio e carbono, foi demonstrada na bioprodução de carotenoides por $R$. glutinis. ${ }^{52}$ Nas condições otimizadas pelo método simplex (método rápido e eficiente para otimização de sistemas multifatoriais), obtevese 3,5 mg/L de carotenoides totais e 10,3 g/L de biomassa, represen- 
tando incremento de 43 e $20 \%$ quando comparados à variação de um único fator, respectivamente.

A levedura Sporobolomyces ruberrimus $\mathrm{H} 110^{44}$ foi cultivada em diferentes fontes de carbono: glicerol puro, glicerol comercial e glicose. O glicerol comercial ( $32 \mathrm{~g} / \mathrm{L})$ propiciou a concentração máxima de carotenoides de $3,8 \mathrm{mg} / \mathrm{g}$, onde se observou a torularrodina $(3,7 \mathrm{mg} / \mathrm{g})$ como carotenoide majoritário, seguida de $\beta$-caroteno $(0,14 \mathrm{mg} / \mathrm{g})$. Com a levedura Sporobolomyces roseus ${ }^{43}$ cultivada em meio YED (30 g/L de glicose, $4 \mathrm{~g} / \mathrm{L}$ de extrato de levedura, $1 \mathrm{~g} / \mathrm{L}$ de $\mathrm{KH}_{2} \mathrm{PO}_{4}$ e $0,5 \mathrm{~g} / \mathrm{L}$ de $\mathrm{MgSO}_{4} \cdot 7 \mathrm{H}_{2} \mathrm{O}$ ), tendo glicose como fonte de carbono, obteve-se uma concentração máxima de carotenoides de $412 \mu \mathrm{g} / \mathrm{g}$, sendo que os carotenoides majoritários foram o toruleno e $\beta$-caroteno.

No cultivo de Sporidiobolus salmonicolor CBS $2636^{53-54} \mathrm{em}$ frascos agitados, verificou-se que o teor de carotenoides totais e a produção específica aumentaram com a elevação das concentrações de glicose, extrato de malte e peptona, obtendo o teor máximo de carotenoides totais de $1019 \mu \mathrm{g} / \mathrm{L}$ no ensaio com $40 \mathrm{~g} / \mathrm{L}$ de glicose, $10 \mathrm{~g} / \mathrm{L}$ de extrato de malte e $14 \mathrm{~g} / \mathrm{L}$ de peptona. Valduga e colaboradores,,${ }^{54-56}$ ao utilizarem substratos industriais pré-tratados com ácidos (sulfúrico e/ ou fosfórico) na bioprodução por $S$. salmonicolor, obtiveram um teor de carotenoides totais de 541,5 $\mu \mathrm{g} / \mathrm{L}$, com concentrações de melaço de cana-de-açúcar de $10 \mathrm{~g} / \mathrm{L}$, água de maceração de milho de $5 \mathrm{~g} / \mathrm{L}$ e hidrolisado de levedura de $5 \mathrm{~g} / \mathrm{L}$.

A salinidade também é um fator que provoca alterações na produção de carotenoides. Na avaliação de duas cepas de $D$. salina $a^{57}$ cultivadas em meios com diferentes salinidades, o meio Johnson foi modificado com a adição de 15 e $23 \%$ de $\mathrm{NaCl}$, enquanto que o meio Provasoli, com 12,5 e $20 \%$ de $\mathrm{NaCl}$. A densidade celular máxima foi obtida no meio Johnson a $15 \%$ de $\mathrm{NaCl}$ em ambas as cepas. Para carotenoides totais, os valores mais altos foram obtidos no meio Provasoli com $20 \% \mathrm{NaCl}(13,3 \mathrm{mg} / \mathrm{L})$ e carotenoides específicos 110,9 pg/cel.

Em frascos agitados, $R$. glutinis DM $28^{5}$ foi cultivada em salmoura de rabanete em várias concentrações, sendo que nas quantidades mais baixas de sólidos solúveis totais (10 a $30 \mathrm{~g} / \mathrm{L})$ a levedura consumiu todo o substrato no final de $24 \mathrm{~h}$. Contudo, a $50 \mathrm{~g} / \mathrm{L}$ de sólidos solúveis totais a levedura apresentou crescimento até o final do cultivo (72 h). Porém, com $70 \mathrm{~g} / \mathrm{L}$ de sólidos solúveis totais ocorreu inibição de crescimento do microrganismo, devido à alta concentração salina e outros componentes químicos do substrato.

Fazeli e colaboradores ${ }^{58}$ avaliaram o efeito de diferentes concentrações salinas $(0,05$ a $3 \mathrm{M} \mathrm{NaCl})$ sobre a cinética de crescimento, carotenoides totais e $\beta$-caroteno acumulados na microalga Dunaliella tertiolecta. A maior quantidade de carotenoides detectada $(11,7 \mathrm{mg} / \mathrm{L})$ foi em salinidade de $0,5 \mathrm{M} \mathrm{NaCl}$ durante a fase estacionária de crescimento, porém nas maiores concentrações salinas $(3 \mathrm{M} \mathrm{NaCl})$ obteve-se maior produção de carotenoides específicos $(2,0 \mathrm{pg} / \mathrm{cel})$. Como na salinidade de $0,5 \mathrm{M}$ obteve-se $32 \%$ de 9 -cis- $\beta$-caroteno na fase exponencial, e $23 \%$ de $\beta$-caroteno na fase estacionária, sugere-se que o acúmulo de carotenoides e também as proporções dos isômeros $\beta$-caroteno não foram afetados somente pela salinidade, mas também pelas fases de crescimento da cultura.

Shih e colaboradores ${ }^{59}$ utilizaram salmoura do resíduo gerado pela indústria de picles fermentados, como substrato para a produção de carotenoides com três cepas de $R$. rubra. A cepa $R$. rubra NRRL Y-15596 apresentou a maior quantidade de carotenoides totais, expressos como $1041 \mu \mathrm{g} / \mathrm{L}$ de $\beta$-caroteno. A levedura removeu completamente a acidez e reduziu em $70 \%$ a demanda bioquímica de oxigênio, demonstrando que esta fermentação pode apresentar valor econômico no tratamento de subprodutos.

Na bioprodução de carotenoides por cepas do gênero Rhodotoru$l a^{50}$ em diferentes substratos (mosto de uva, xarope de glicose, melaço de beterraba, extrato de farinha de soja e extrato de farinha de milho), obteve-se rendimento máximo de carotenoides totais $(5,9 \mathrm{mg} / \mathrm{L})$ e carotenoides específicos $(630 \mu \mathrm{g} / \mathrm{g})$ para a cepa $R$. glutinis cultivada em mosto de uva concentrado ( $820 \mathrm{~g} / \mathrm{L}$ do total de carboidratos).

Na produção de carotenoides por $R$. glutini ${ }^{24}$ utilizando substratos de baixo custo (glicose, sacarose de melaço e lactose do soro de queijo), a maior concentração de carotenoides totais $(125 \mathrm{mg} / \mathrm{L})$ foi obtida com $20 \mathrm{~g} / \mathrm{L}$ de sacarose de melaço; enquanto que o maior rendimento de produto baseado na máxima concentração celular $(35,5 \mathrm{mg} / \mathrm{g})$ foi alcançado com a lactose do soro na concentração de 13,2 g/L. Os resultados comprovaram que a $R$. glutinis é um microrganismo promissor para a utilização industrial.

\section{Efeito do pH}

A biossíntese de carotenoides naturalmente ocasiona mudanças do $\mathrm{pH}$ do meio de cultivo, como consequência do crescimento de leveduras. De modo geral, o $\mathrm{pH}$ do meio decresce nas primeiras $72 \mathrm{~h}$ de bioprodução, seguido de uma elevação durante a fase intensa de carotenogênese. A partir daí, o $\mathrm{pH}$ permanece constante indicando o final da bioprodução. ${ }^{60}$

$\mathrm{O}$ pH é um dos parâmetros ambientais mais importantes que exercem influência no crescimento celular e formação de produto. Desta forma, o pH inicial é objeto de estudo na produção de carotenoides. Para a levedura $S$. ruberrimus, ${ }^{44} \mathrm{o} \mathrm{pH}$ inicial apresentou um intenso efeito sobre o conteúdo de carotenoides e biomassa. O conteúdo mínimo de carotenoides e células foi observado com cultivo a $\mathrm{pH}$ 3,5 (biomassa: 6,8 g/L; carotenoides específicos: $2,0 \mathrm{mg} / \mathrm{g}$ ). A carotenogênese e o crescimento foram induzidos pela elevação do $\mathrm{pH}$ de 3,5 a 6,0, sendo pH 6,0 ótimo para o crescimento celular (11,3 g/L) e formação de pigmento $(38,7 \mathrm{mg} / \mathrm{L})$.

Alguns trabalhos indicam que as condições ótimas para a produção de carotenoides não são as mesmas que para o crescimento celular. Em estudo com $P$. rhodozyma,${ }^{61}$ verificou-se que o $\mathrm{pH}$ inicial ótimo de crescimento foi de 5,8, enquanto que a máxima produção de astaxantina foi a $\mathrm{pH} 5,0$.

$\mathrm{O}$ efeito do $\mathrm{pH}$ inicial na concentração de carotenoides e biomassa de $S$. salmonicolor em frascos agitados também foi avaliado por Valduga e colaboradores, ${ }^{54,55}$ que verificaram que o melhor $\mathrm{pH}$ de crescimento se encontra entre 4,0 e 5,0, enquanto que a máxima produção de carotenoides se dá em $\mathrm{pH} 4,0$.

Em estudo realizado por Ramírez e colaboradores, ${ }^{7}$ no screening de variáveis com meio Yuca $\left(2 \mathrm{~g} / \mathrm{L}\right.$ de $\mathrm{KH}_{2} \mathrm{PO}_{4} ; 0,5 \mathrm{~g} / \mathrm{L}$ de $\mathrm{MgSO}_{4}$; suplementado com suco de tâmara e ureia), o pH foi um dos parâmetros de maior efeito na produção de pigmento por $P$. rhodozyma, bem como a interação entre $\mathrm{pH}$ e temperatura. As menores concentrações de pigmento foram obtidas com os valores mais baixos de $\mathrm{pH}(4,0)$ e temperatura $\left(16{ }^{\circ} \mathrm{C}\right)$; enquanto que com $\mathrm{pH}$ mais elevado $(6,0) \mathrm{e}$ na mesma temperatura se observou aumento na síntese de corante. Porém, com temperatura elevada $\left(22^{\circ} \mathrm{C}\right)$, a variável $\mathrm{pH}$ não apresentou efeito significativo $(\mathrm{p}<0,05)$. Nos experimentos realizados com meio $\mathrm{YM}$ ocorreram diferenças em relação ao efeito do $\mathrm{pH}$, sendo que em pH 4,0 diminuiu drasticamente a concentração celular e a produção de astaxantina, independentemente da temperatura. A menor síntese de pigmentos foi observada no menor valor de $\mathrm{pH}(4,0)$ e inóculo (5\%), enquanto que em pH 6,0 a porcentagem de inóculo não apresentou efeito.

Aksu e Eren ${ }^{19}$ verificaram que o $\mathrm{pH}$ do meio de cultivo não influenciou somente a atividade biossintética da levedura $R$. mucilagino$s a$, mas também na taxa de crescimento da cultura. Com a elevação do pH de 3,0 para 7,0 observaram um aumento nas taxas de crescimento e produção de carotenoides, com decréscimo em $\mathrm{pH}$ superior. Em outro caso, a levedura $R$. glutinis, estudada por Tinoi e colaboradores, ${ }^{52}$ 
apresentou um pH ótimo para o crescimento de 5,91, confirmando a preferência geral das leveduras por $\mathrm{pH}$ levemente ácido.

Shih e Hang ${ }^{59}$ observaram que em $\mathrm{pH}$ baixos, na faixa de 3,4 a 4,5 , ocorreu inibição do crescimento celular e da produção de carotenoides por $R$. rubra, sendo que a máxima concentração celular $(131 \mu \mathrm{g} / \mathrm{L})$ e produção $(1041 \mu \mathrm{g} / \mathrm{L}$ de $\beta$-caroteno) foram obtidas em $\mathrm{pH}$ inicial de 5,0.

Os efeitos do $\mathrm{pH}$ (inicial e controlado) foram estudados durante o cultivo de $X$. dendrorhous ${ }^{22}$ para produção de astaxantina. Na bioprodução em frascos agitados foram observados $\mathrm{pH}$ iniciais ótimos de 6,0 para crescimento celular (17,2 g/L) e 5,0 para produção de astaxantina (20,4 mg/L). Em relação ao pH controlado no biorreator, obtiveram-se as seguintes respostas para concentração de astaxantina: pH 4,0 - 17,7 mg/L, pH 5,0 - 21,8 mg/L e pH 6,0 - 18,8 mg/L. Para crescimento celular, a maior concentração de biomassa foi obtida a $\mathrm{pH}$ 6,0 (17,2 g/L). Em função da variabilidade dos resultados, os autores desenvolveram uma estratégia de controle de $\mathrm{pH}$ com a finalidade de aumentar a produção de astaxantina. Como o fator de conversão $\mathrm{Y}_{\mathrm{P} / \mathrm{X}}(1,5 \mathrm{mg} / \mathrm{g})$ mais elevado foi em $\mathrm{pH}$ 4,0 e o maior crescimento celular foi em $\mathrm{pH} 6,0$, os mesmos realizaram a bioprodução onde nas primeiras 80 h manteve-se pH 6,0 e na sequência em pH 4,0. Com essa estratégia de cultivo, a concentração de astaxantina foi de $27,0 \mathrm{mg} / \mathrm{L}$, proporcionando um aumento de $24,1 \%$ em comparação com o cultivo em $\mathrm{pH}$ constante.

\section{Efeito da temperatura}

A temperatura é um dos fatores ambientais mais importantes que influenciam o crescimento e o desenvolvimento dos microrganismos, causando alterações em muitas vias biossintéticas, inclusive na carotenogênese. Segundo Hayman e colaboradores, ${ }^{3}$ a temperatura exerce controle na concentração de enzimas envolvidas na produção de carotenoides e mudanças na concentração enzimática, definitivamente controla o nível de carotenoides nos microrganismos.

A concentração relativa de cada carotenoide foi alterada pela temperatura de cultivo por $R$. glutinis. ${ }^{62}$ Quando a levedura foi cultivada em $5{ }^{\circ} \mathrm{C}$, ocorreu a produção predominante de $\beta$-caroteno, enquanto que o cultivo a $25^{\circ} \mathrm{C}$ levou à síntese de toruleno e torularrodina. $\mathrm{O}$ crescimento celular ótimo foi obtido a $30{ }^{\circ} \mathrm{C}$. Nesta mesma temperatura, a máxima produção de carotenoides foi de $8388 \mu \mathrm{g} / \mathrm{L}$ e $31,9 \mathrm{~g} / \mathrm{L}$ de biomassa.

$\mathrm{O}$ efeito de três níveis de temperatura sobre o crescimento e a produtividade de carotenoides na levedura $R$. mucilaginosa foi avaliado por Aksu e Eren. ${ }^{19}$ Com a elevação da temperatura de 25 para 30 ${ }^{\circ} \mathrm{C}$, verificaram um aumento nas taxas de formação de carotenoides e crescimento específico, sendo que estas diminuíram bruscamente acima de $30{ }^{\circ} \mathrm{C}$. Tal comportamento é devido à desnaturação do sistema enzimático do microrganismo exposto à alta temperatura. Assim, para $R$. mucilaginosa a temperatura ótima de cultivo foi de $30{ }^{\circ} \mathrm{C}$ com uma produção de $69,8 \mathrm{mg} / \mathrm{L}$ de carotenoides e $5,1 \mathrm{~g} / \mathrm{L}$ de biomassa, respectivamente.

Em outra investigação estudando a produção de carotenoides com R. glutinis, ${ }^{24}$ obteve-se comportamento semelhante ao da $R$. mucilaginosa. A taxa de crescimento específico da levedura aumentou com a elevação da temperatura de 25 para $30^{\circ} \mathrm{C}$, de aproximadamente 0,175 para $0,238 \mathrm{~h}^{-1} \mathrm{e}$, diminuiu de maneira drástica em temperatura superior a $30^{\circ} \mathrm{C}\left(\sim 0,14 \mathrm{~h}^{-1}\right)$.

A levedura $R$. glutinis ${ }^{63}$ apresentou-se sensível ao fator temperatura em relação ao crescimento celular. Em condições otimizadas obteve-se concentração de carotenoides totais de $3,5 \mathrm{mg} / \mathrm{L}$ e 10 , $3 \mathrm{~g} / \mathrm{L}$ de células. Das temperaturas testadas ( 9 níveis), a faixa ótima de crescimento foi de 28 a $30{ }^{\circ} \mathrm{C}$, comportamento típico do gênero.

Valduga e colaboradores ${ }^{53}$ testaram o cultivo de $S$. salmonicolor
CBS 2636 em três temperaturas distintas: 20,28 e $35^{\circ} \mathrm{C}$, observando efeito negativo da temperatura sobre a produção de carotenoides totais e específicos.

O estudo da influência da temperatura sobre o crescimento celular e produção de carotenoides da levedura $S$. ruberrimus foi analisado por Razavi e March, ${ }^{44}$ sendo observado crescimento na produção celular enquanto se manteve a temperatura entre 19 e $27^{\circ} \mathrm{C}$. No entanto, em temperaturas superior a $27^{\circ} \mathrm{C}$ ocorreu crescimento celular, porém as células não apresentaram coloração. A produção dos carotenoides foi acentuada durante a fase exponencial na maioria das temperaturas, com exceção a $31^{\circ} \mathrm{C}$. A temperatura ótima de bioprodução foi de 19 ${ }^{\circ} \mathrm{C}$, onde a torularrodina foi sintetizada em quantidade superior ao -caroteno, de 120 e $5 \mathrm{mg} / \mathrm{L}$, respectivamente.

Para a otimização da produção de carotenoides por $P$. rhodozyma, a temperatura foi o fator que mais influenciou na produção de astaxantina. Ramírez e colaboradores, ${ }^{7}$ testando diferentes temperaturas, observaram que para as cepas selvagens e mutante de $P$. rhodozyma as temperaturas ótimas foram de 22 e $19,7^{\circ} \mathrm{C}$, respectivamente.

\section{Efeito da luminosidade}

A produção e o acúmulo de carotenoides são positivamente afetados pela irradiação de luz branca em algas, fungos e bactérias. Contudo, a intensidade e forma de iluminação variam com o microrganismo. A teoria da foto indução pode ser descrita em dois aspectos; no primeiro, o efeito da luz sobre o crescimento do microrganismo exerce papel fundamental, como estimulante da produção; o segundo aspecto considera que o acúmulo de carotenoides na célula está associado com o aumento da atividade das enzimas envolvidas na biossíntese de carotenoides..$^{25}$

Alguns trabalhos demonstram que determinadas leveduras biossintetizam carotenoides contra os danos causados pela luz. Os efeitos da luz branca sobre o crescimento e a produção de carotenoides por $R$. glutinis foram avaliados por Sakaki e colaboradores. ${ }^{42}$ Para a levedura não pigmentada Saccharomyces cerevisiae uma fraca irradiação de luz branca não apresentou efeito sobre o crescimento das células, no entanto, na levedura selvagem $R$. glutinis, a luz inibiu o crescimento celular, onde simultaneamente, a produção de torularrodina aumentou de 7,9 para 14,2 mg/100g células, durante a fase exponencial. Os resultados demonstram a potente habilidade da torularrodina sequestrar o oxigênio singlete.

Em estudo realizado visando a otimização da produção de astaxantina e células por $H$. pluvialis, ${ }^{64} \mathrm{o}$ crescimento foi avaliado sob duas densidades de fluxo de fótons de 35 e $85 \mu \mathrm{mol} / \mathrm{m}^{2} \mathrm{~s}$. No entanto, a carotenogênese foi induzida por uma densidade luminosa de $150 \mu \mathrm{mol} / \mathrm{m}^{2} \mathrm{~s}$. O conteúdo de carotenoides cultivados em nitrato a $35 \mu \mathrm{mol} / \mathrm{m}^{2} \mathrm{~s}$ e sujeito à alta luminosidade $\left(150 \mu \mathrm{mol} / \mathrm{m}^{2} \mathrm{~s}\right)$ aumentou de 1,7 para $4,8 \mathrm{mg} / \mathrm{L}$.

Alguns estudos sugerem que a alga $H$. pluvialis pode acumular aproximadamente $3 \%$ de astaxantina em relação ao peso da célula seca quando exposta à luz solar ou lâmpadas fluorescentes ou halógenas. ${ }^{65,66} \mathrm{~A}$ luz azul aumentou a biossíntese de astaxantina na $H$. pluvialis $^{65,67,68}$ e elevou o conteúdo deste pigmento em aproximadamente $7 \%$ sob luminosidade emitida de diodos de luz azul (LEDs). ${ }^{67}$

Estudos realizados por Johnson e Gil-Hwan, ${ }^{69}$ utilizando alta intensidade luminosa mostraram que a luz inibiu o crescimento celular e a formação de pigmento, houve produção de $\beta$-zeacaroteno, indicando a ocorrência de estresse celular. A levedura $P$. rhodozy$m a,{ }^{8}$ quando cultivada sob iluminação, produziu astaxantina como principal carotenoide. Entretanto, quando esta levedura foi cultivada na ausência de luz, o carotenoide principal encontrado foi o HDCO (3-OH-3',4'-dide-hidro- $\beta$ - $\Psi$-caroteno-4-ona), com concentração acima de $0,75 \mathrm{mg} / \mathrm{L}$. 


\section{Efeito da taxa de aeração e agitação}

Os microrganismos aeróbicos assim como $P$. rhodozyma, cujo crescimento (metabolismo primário) é dependente do fornecimento de oxigênio, necessitam de definição das melhores condições de aeração e agitação para aumento de rendimento. Segundo Yamane e colaboradores, ${ }^{41}$ a taxa de produção de astaxantina por $P$. rhodozyma aumenta com a elevação do fornecimento de oxigênio.

Liu e colaboradores ${ }^{6}$ estudaram os efeitos da transferência de oxigênio em frascos agitados em $P$. rhodozyma. Os autores observaram que com $30 \mathrm{~h}$ de bioprodução a concentração de oxigênio dissolvido na fase líquida era próxima de zero $(3,5 \%)$, enquanto que na fase gasosa, a concentração de oxigênio diminuiu lentamente nas primeiras $30 \mathrm{~h}$ (10\%) e permaneceu em altas concentrações. Devido ao comportamento observado em ambas as fases definiram que esta era a etapa limitante do transporte de oxigênio. No mesmo trabalho foi evidenciado que o aumento da agitação (200 a $250 \mathrm{rpm}$ ) e a diminuição do volume de líquido (50 a $20 \mathrm{~mL}$ ) ocasionaram elevações no crescimento celular (8 a 10,7 g/L) e produção de carotenoides (7,4 a 15,5 mg/L), sendo que a mudança na velocidade de agitação apresentou maior efeito no rendimento de carotenoides nos maiores volumes de líquido. $\mathrm{O}$ coeficiente de transferência de oxigênio diminuiu com a redução do volume de líquido e aumentou com a velocidade de agitação.

$\mathrm{Na}$ avaliação da influência da aeração sobre o conteúdo de carotenoides das leveduras $S$. roseus e $R$. glutinis, ${ }^{43}$ observou-se que para $R$. glutinis a maior taxa de aeração (frascos com entalhes) permite obter maior concentração de carotenoides, um aumento de 113 para $206 \mu \mathrm{g} / \mathrm{g}$, embora o perfil de carotenoides permaneça inalterado. No entanto para $S$. roseus, o aumento na aeração proporcionou o incremento na concentração de carotenoides de 109 para $412 \mu \mathrm{g} / \mathrm{g}$, porém ocorreu mudança no conteúdo dos carotenoides específicos, indicando uma mudança biossintética.

Aksu e Eren ${ }^{19}$ observaram um aumento nas taxas específicas de crescimento e de formação de carotenoides com a elevação das taxas de aeração ( 0 a 2,4 vvm) para $R$. mucilaginosa, obtendo biomassa de $5,7 \mathrm{~g} / \mathrm{L}$, carotenoides totais $112,8 \mathrm{mg} / \mathrm{L}$ e rendimento de produto de $19,8 \mathrm{mg} / \mathrm{g}$. Assim, a aeração mostrou-se benéfica para o crescimento celular, devido a melhorias nas características de transferência de massa com respeito a substrato, produto e oxigênio. O mesmo comportamento foi observado com a levedura $R$. glutinis, ${ }^{24}$ obtendo-se biomassa de $5,4 \mathrm{~g} / \mathrm{L}$, carotenoides totais $105,8 \mathrm{mg} / \mathrm{L}$ e rendimento de produto de $19,6 \mathrm{mg} / \mathrm{g}$.

Tinoi e colaboradors, ${ }^{52} \mathrm{em}$ frascos agitados, verificaram que em taxas de agitação baixas (100 a $150 \mathrm{rpm}$ ) tem-se menor crescimento celular, devido à diminuição da disponibilidade de nutrientes na superfície das células. Ao contrário, em altas taxas de agitação (>250 rpm) ocorreu ruptura celular evidenciada pelo aparecimento de uma fina camada oleosa.

Valduga e colaboradoes ${ }^{53}$ realizaram um screening de variáveis na bioprodução de carotenoides em frascos agitados por $S$. salmonicolor CBS 2636, observando que a agitação (150 a $200 \mathrm{rpm}$ ) exerceu efeito positivo significativo $(\mathrm{p}<0,05)$ sobre a concentração de carotenoides totais, carotenoides específicos e biomassa.

As pesquisas de produção de corantes naturais utilizando microrganismos vêm enfocando não somente a seleção de linhagens produtoras de uma variedade de carotenoides, mas também a otimização das metodologias de cultivo para um aumento na produção de corante, redução de custos com a bioprodução e posterior aplicação em escala industrial. Além disso, inúmeros trabalhos são realizados aplicando engenharia genética visando a obtenção de carotenoides de maior interesse e em maiores quantidades.

A tendência é o aumento nas pesquisas em relação à produção de corantes através de microrganismos, pois se tem a necessidade de redução de custos de produção e aumento no rendimento, tornando assim a bioprodução competitiva com a síntese química.

\section{PRODUÇÃO INDUSTRIAL E ANÁLISE DE MERCADO DOS CAROTENOIDES}

A produção industrial de $\beta, \beta$-caroteno começou em $1954 \mathrm{e}$, desde então, a síntese comercial de carotenoides vem sendo desenvolvida. Atualmente, são vendidos por ano cerca de US\$ 300 milhões em carotenoides sintéticos. Os dois principais produtores industriais, Hoffmann-La Roche e BASF, produzem seis diferentes carotenoides, o $\beta, \beta$-caroteno, a cantaxantina, a astaxantina (mistura de dois enantiômeros e a forma meso), os apocarotenoides e a citranaxantina (C33). ${ }^{70}$

Uma parte dispendiosa, apesar de essencial, do processo industrial é a transformação do composto lipofílico, cristalino e puro em formulações que são apropriadas para a aplicação industrial. A dispersão microcristalina do carotenoide em uma gordura comestível é usada na produção de margarinas. Pós contendo carotenoides como uma microdispersão em um coloide protetor hidrofílico são usados para meios aquosos, tais como suco de frutas. ${ }^{70}$

O preço de mercado, por grama, é em torno de $\mathrm{R} \$ 57$ para o $\beta, \beta$-caroteno, e R $\$ 633$ para a astaxantina, já um miligrama de zeastaxantina chega a custar $\mathrm{R} \$ 1690 .{ }^{71}$

Os pigmentos produzidos por métodos biológicos têm surgido como um crescente segmento do mercado industrial. Eles são aplicados em alimentos, como suplemento nutricional, e em indústrias cosmética e farmacêutica. Desde o início dos anos 80, várias companhias biotecnológicas têm desenvolvido métodos para produzir pigmentos em culturas bacterianas, de algas e fungos. ${ }^{72}$

Os biopigmentos normalmente entram em mercados existentes para pigmentos obtidos por síntese química. Para sobreviver, os materiais produzidos biologicamente devem oferecer vantagens em seu emprego, custo e/ou conformidade com as normas. As três principais categorias emergentes de biopigmentos deste mercado são carotenoides, xantofilas e melanina. ${ }^{73}$

Somente os aditivos de cor que estão registrados no Code of Federal Regulations (CFR) podem ser usados legalmente nos Estados Unidos para promover a coloração do salmão e outros animais utilizados como alimento. A astaxantina foi recentemente relacionada pelo Food and Drug Administration (FDA) como um aditivo para pigmentar somente a carne de salmonídeos e o limite permitido foi de $8 \mathrm{mg}$ de pigmento por quilograma de alimento para peixe. ${ }^{8}$ A cantaxantina está registrada no CFR como um aditivo de cor, mas ainda não foi aprovada pelo FDA. Porém, a astaxantina, e não a cantaxantina, é normalmente encontrada no salmão selvagem. ${ }^{74}$

No final de 2003, o mercado europeu de carotenoides contabilizou um total de US\$ 348,5 milhões, sendo as previsões para 2010 de até US \$ 419,6 milhões, ${ }^{75}$ com um mercado global estimado de US\$ 935 milhões/ano. ${ }^{76} \mathrm{O}$ mercado de astaxantina, embora menor que o de licopeno e $\beta$-caroteno, tem crescido rapidamente, sendo previsto um aumento da sua participação no mercado de $26 \%$ entre 2000 e 2010 . O segmento de aditivos de alimentação animal será o mais lucrativo até o ano de 2010, seguido pelo de suplementos e alimentos fortificados. ${ }^{75}$

A luteína, nos últimos anos, destaca-se pelos benefícios relacionados com a saúde da visão. Antes do fim da década de 1990 a luteína era usada principalmente para colorir gema de ovo e carne de frango. A partir de 2000, uma nova aplicação da luteína desenvolve-se, na forma de suplemento, para prevenir a doença da degeneração macular. Esta nova aplicação levou o mercado da luteína para mais de 139 milhões de dólares em 2004, comparado com 64 milhões em 1999. ${ }^{72,75}$

\section{REFERÊNCIAS}

1. Niizu, P. Y.; Dissertação de Mestrado, Universidade Estadual de Campinas, Brasil, 2003. 
2. Silva, M. C.; Tese de Doutorado, Universidade Estadual de Campinas, Brasil, 2004.

3. Hayman, E. P.; Yokoyama, H.; Chichester, C. O.; Simpson, K. L.; J. Bacteriol. 1974, 120, 1339.

4. Li, Z.; Yuan, H.; Hu, X.; Bioresour. Technol. 2008, 99, 1339.

5. Malisorn, C.; Suntornsuk, W.; Bioresour. Technol. 2008, 99, 2281.

6. Liu, Y.-S.; Wu, J.-Y.; Ho, K.-P.; Biochem. Eng. J. 2006, 27, 331.

7. Ramírez, J.; Gutierrez, H.; Gschaedler, A.; J. Biotechnol. 2001, 88, 259.

8. Vázquez, M.; Santos, V.; Biotechnol. Lett. 1998, 20, 181.

9. Buzzini, P.; Innocenti, M.; Turchetti, B.; Libkind, D.; Broock, M.; Mulinacci, N.; Can. J. Microbiol. 2007, 53, 1024.

10. Maldonade, I. R.; Rodriguez-Amaya, D. B.; Scamparini, A. R. P.; Food Chem. 2008, 107, 145.

11. López-Nieto, M. J.; Costa, J.; Peiro, E.; Méndez, E.; Rodríguez-Sáiz, M.; de la Fuente, J. L.; Cabri, W.; Barredo, J. L.; Appl. Microbiol. Biotechnol. 2004, 66, 153.

12. Mantzouridou, F.; Roukas, T.; Kotzekidou, P.; Biochem. Eng. J. 2002, $10,123$.

13. Hejazi, M. A.; Holwerda, E.; Wijffels, R. H.; Biotechnol. Bioeng. 2004, 85,475 .

14. Hu, C.-C.; Lin, J.-T.; Lu, F.-J.; Chou, F.-P.; Yang, D.-J.; Food Chem. 2008, 109, 439 .

15. Domínguez-Bocanegra, A. R.; Legarreta, I. G.; Jeronimo, F. M.; Campocosio, A. T.; Bioresour. Technol. 2004, 92, 209.

16. López, M. C. G.-M.; Sánchez, E. D. R.; López, J. L. C.; Fernández, F. G. A.; Sevilla, J. M. F.; Rivas, J.; Guerrero, M. G.; Grima, E. M.; J. Biotechnol. 2006, 123, 329.

17. Katsuda, T.; Shiraishi, H.; Ishizu, N.; Ranjbar, R.; Katoh, S.; J. Biosci. Bioeng. 2008, 105, 216.

18. Ranjbar, R.; Inoue, R.; Shiraishi, H.; Katsuda, T.; Katoh, S.; Biochem. Eng. J. 2008, 39, 575 .

19. Aksu, Z.; Eren, A.T.; Process Biochem. 2005, 40, 2985.

20. Buzzini, P.; Martini, A.; Gaetani, M.; Turchetti, B.; Pagnoni, U. M.; Davoli, P.; Enzyme Microb. Technol. 2005, 36, 687.

21. Garbayo, I.; Vílchez, C.; Nava-Saucedo, J. E.; Barbotin, J. N.; Enzyme Microb. Technol. 2003, 33, 629.

22. Hu, Z.-C.; Zheng, Y.-G.; Wang, Z.; Shen, Y.-C.; Enzyme Microb. Technol. 2006, 39, 586.

23. Maldonade, I. R.; Scamparini, A. R. P.; Rodriguez-Amaya, D. B.; Brazilian J. Microbiol. 2007, 38, 65.

24. Aksu, Z.; Eren, A.T.; Eng. J. 2007, 35, 107.

25. Bhosale, P.; Appl. Microbiol. Biotechnol. 2004, 63, 351.

26. Agarwal, S.; Rao, A. V.; Lipids 1998, 33, 981.

27. Edge, R.; McGarvey, D. J.; Truscott, T. G.; J. Photochem. Photobiol., B 1997, 41, 189.

28. Sánchez-Contreras, A.; Jiménez, M.; Sanchez, S.; Appl. Microbiol. Biotechnol. 2000, 54, 528.

29. Marasco, E.; Schimdt-Dannert, C.; Appl. Biotechnol. Food Sci. Policy 2003, 3, 145.

30. Johnson, E. A.; Schroeder W. A.; J. Biol. Chem. 1995, 270, 374.

31. Gross, J.; Pigments in vegetables: chlorophylls and carotenoids, Van Nostrand Reinhold: New York, 1991.

32. Botella-Pavía, P.; Rodríguez-Concepción, M.; Physiol. Plant 2006, 126, 369.

33. Olivier, J.; Palou, A.; J. Chromatogr., A 2000, 881, 543.

34. Pfander, H.; Key to Carotenoids, $2^{\text {nd }}$ ed., Birkhauser: Basel, 1987.

35. Goodwin, T. W.; The Biochemistry of the carotenoids: Biosynthesis, Chapman and Hall: London, 1981, vol. 1, p. 578-602.

36. Feovila, G. I.; Appl. Bioch. Bioeng. 1994, 30, 143.

37. Borowitzka, L. J.; Borowitzka, M. A. Em Microbial carotenoids; Vandamme, J. E. ed.; Elsevier Applied Science: New York, 1989.

38. Dufossé, L.; Galaup, P.; Yaron, A.; Arad, S. M.; Blanc, P.; Murthy, K. N. C.; Ravishankar, G. A.; Trends Food Sci. Technol. 2005, 16, 389.
39. Fang, T. J.; Wang, J.-M.; Process Biochem. 2002, 37, 1235.

40. Liu, Y. S.; Wu, J. Y.; Biochem. Eng. J. 2007, 36, 182.

41. Yamane, Y.; Higashida, K.; Nakashimada, Y.; Kakinozo, T.; Nishio, N.; Appl. Environ. Microbiol. 1997, 63, 4471.

42. Sakaki, H.; Nakanishi, T.; Tada, A.; Miki, W.; Komemushi, S.; J. Biosci. Bioeng. 2001, 92, 294.

43. Davoli, P.; Mierau, V.; Weber, R. W. S.; Appl. Biochem. Microbiol. 2004, 40, 392.

44. Razavi, S. H.; March, I.; Iranian J. Chem. Eng. 2006, 23, 59.

45. Fontana, J. D.; Czeczuga, B.; Bonfim, T. M. B.; Chociai, M. B.; Oliveira, B. H.; Guimarães, M. F.; Baron, M.; Bioresour. Technol. 1996, 58, 121.

46. Ramírez, J. J. C.; Arellano, M.; Herrera, E.; Vázquez, E. N. O.; Rev. Dig. Cient.Tecnol.Gnosis. 2006, 4, 1.

47. Park, P. K.; Kim, E. Y.; Chu, K. H.; Sep. Purif. Technol. 2007, 53, 148.

48. García-González, M.; Moreno, J.; Manzano, J. C.; Florencio, F. J.; Guerrero, M. G.; J. Biotechnol. 2005, 115, 81.

49. Tatsch, P.; Dissertação de Mestrado, Universidade Regional Integrada do Alto Uruguai e Missões, Brasil, 2008.

50. Buzzini, P.; Martini, A.; Bioresour. Technol. 1999, 71, 41

51. Sutherland, F. C. W.; Kilian, A. G.; Meyer, P. S.; Preez, J. C.; Biotechnol. Lett. 1996, 18, 975 .

52. Tinoi, J.; Rakariyatham, N.; Deming, R. L.; Process Biochem. 2005, 40, 2551.

53. Valduga, E.; Valerio, A.; Treichel, H.; Furigo, A. J.; Di Luccio, M.; Food Bioprocess Technol. 2009, 2, 415.

54. Valduga, E.; Valério, A.; Tash, P.;Treichel, H.; Furigo, A. J.; Di Luccio, M.; Food Bioprocess Techonol. (2008), doi 10.1007/s11947-008-0133-3.

55. Valduga, E.; Valério, A.; Jacques, A.R.; Treichel, H.; Furigo, A. J.; Di Luccio, M.; Quim. Nova 2007, 30, 1860.

56. Valduga, E.; Valério, A.; Treichel, H.; Furigo, A. J.; Di Luccio, M.; J. Chem. Technol. Biotechnol. 2008, 83, 9,1267.

57. Aguilar, C. P.; González, M.; Cifuentes, A. S.; Silva, M.; J. Chil. Chem. Soc. 2004, 49, 1.

58. Fazeli, M. R.; Tofighi, H.; Samadi, N.; Jamalifar, H.; Bioresour. Technol. 2006, 97, 2453.

59. Shih, C. T.; Hang, Y. D.; Lebensm.-Wiss. U.-Technol. 1996, $29,570$.

60. Frengova, G.; Simova, E.; Pavlova, K.; Beshkova, D.; Grigorova, D.; Biotechnol. Bioeng. 1994, 44, 888.

61. Jonhson, E. A.; Gil-Hwan, A. N.; Crit. Rev. Biotechnol. 1991, 11, 297.

62. Frengova, G. I.; Simova, E. D.; Beshkova, D. M.; Biotechnol. Lett. 1995, 17,1001 .

63. Uenojo, M.; Junior, M. R. M.; Pastore, G. M.; Quim. Nova 2007, 30, 616.

64. González, M. A.; Cifuentes, A. S.; Vargas, S.; Hoeneisen, M.; González, N.; Biol. Res. 2003, 36, 3.

65. Kobayashi, M.; Kakizono, T.; Nishio, N.; Nagai, S.; J. Ferment. Bioeng. 1992, 74, 61 .

66. Lorenz, R. T.; Cysewski, G. R.; Trends Biotechnol. 2000, 18, 160.

67. Katsuda, T.; Lababpour, A.; Shimahara, K.; Katoh, S.; Enzyme Microb. Technol. 2004, 35, 81.

68. Park, E. K.; Lee, C. G.; Microbiol. Biotechnol. 2001, 11, 1024.

69. Jonhson, E. A.; Gil-Hwan, A. N.; J. Microbiol. Serology 1990, 57, 191.

70. Britton, G. Em Carotenoids: Spectroscopy; Britton, G.; Liaaen-Jensen, S.; Pfander, H., eds.; Basel: Birkhäuser, 1995, vol. 1B, p. 13-62.

71. https://www.sigmaaldrich.com, acessada em Janeiro 2009.

72. Passos, R.; Tese de Doutorado, Universidade Federal de Santa Catarina, Brasil, 2007.

73. Dean, K. L.; Ind. Bioprocess 1992, 14, 4.

74. Turujman, S. A.; Wamer, W. G.; Wei, R. R.; Albert, R. H.; J. AOAC Int. 1997, 80, 622 .

75. http://www.nutraingredients.com, acessada em Janeiro 2009.

76. Fraser, P. D; Bramley, P. M.; Prog.Lipid Res. 2004, 43, 228. 